\title{
PENERAPAN PERATURAN MENTERI HUKUM DAN HAM NO 32 TAHUN 2018 PADA UNIT PELAKSANA TEKNIS PEMASYARAKATAN
}

\author{
Danang Wisnu Santoso \\ Politeknik IImu Permasyarakatan \\ Email: danangwisnusantoso@gmail.com \\ Depok, 16514, Indonesia
}

\begin{abstract}
The purpose of this paper is to examine the application of the regulation of the Minister of Law and Human Rights No. 32 of 2018 concerning the treatment of elderly prisoners and convicts, where the regulation can be used as a reference for the Correctional Technical Implementation Unit to carry out services for elderly inmates.

The research method uses a qualitative descriptive approach. trying to explain by describing the conditions that exist in the Technical Implementing Unit in providing services to elderly prisoners and comparing it with PermenKUMHAM No. 32 of 2018. The results of the study explain that the implementation of PermenKumHAM No. 32 of 2018 in the Correctional Technical Implementation Unit has not been evenly implemented. , but that does not mean that it is not carried out at all in the technical implementing unit.
\end{abstract}

Keywords: Application; Elderly; Ministerial regulation; Prisoners; Service

\section{Abstrak}

Tujuan tulisan ini adalah untuk mengkaji penerapan peraturan Menteri Hukum dan Ham No.32 Tahun 2018 tentang perlakuan bagi tahanan dan narapidana lanjut usia, dimana peraturan tersebut dapat dijadikan sebagai acuan Unit Pelaksana Teknis pemasyarakatan untuk melaksanakan pelayanan terhadap WBP lansia. Metode penelitian menggunakan pendekatan deskriptif kualittif. berusaha menjelaskan dengan cara menggambarkan keadaan yang ada pada Unit Pelaksana Teknis dalam pemberian pelayanan terhadap narapidana lansia dan membandingkan dengan PermenKUMHAM No.32 Tahun 2018. Hasil penelitian menjelaskan bahwa Penerapan PermenKumHAM No.32 Tahun 2018 pada Unit Pelaksanan Teknis Pemasyarakatan memang belum semua merata di laksanakan, namun bukan berarti tidak samasekali dilakukan pada unit pelaksana teknis tersebut.

Kata Kunci: Penerapan; Peraturan Menteri; Lanjut Usia; Pelayanan; Narapidana

Open Access at:http://ojs.uho.ac.id/index.php/PUBLICUHO/index Journal Publicuho is licensed under a Creative Commons Attribution 4.0 International License. 


\section{Journal Publicuho}

ISSN2621-1351 (online), ISSN 2685-0729 (print)

Volume 4 Number 3 (August - October), (2021) pp. 956-960

Accredited SINTA SK.NOMOR 28/E/KPT/2019

Open Access at:http://ojs.uho.ac.id/index.php/PUBLICUHO/index

DOI: 10.35817/jpu.v4i3.20950

\section{PENDAHULUAN}

Pemasyarakatan merupakan kegiatan untuk melakukan pembinaan warga binaan pemasyarakatan yang didasarkann pada sistem, kelembagaan, dan cara pembinaan yang merupakan bagian akhir dari sistem pemidanaan dalam tata peradilan pidana.. Dimana tujuan utamanya adalah untuk mengembalikan fitrah narapidana menjadi manusia seutuhnya. Dalam usaha mengembalikan hidup, kehidupan, dan penghidupan seorang narapidana pemasyarakatan memiliki kewajiban dalam memberikan pembinaan serta perawatan yang tidak diskriminatif terhadap seluruh warga Binaan pemasyarakatan. Dalam UU No.12 tahun 1995 diatur bahwa Warga Binaan Pemsayarakatan digolongkan berdasarkan Umur, Jenis kelamin, lama pidana, serta jenis kejahatan. Pengklasifikasian ini bertujuan dalam menentukan pembinaan dan pelayanan yang diberikan kepada Narapidana tersebut

Dalam penelitian ini penulis berfokus pada narapidana lansia dimana narapidana lansia termasuk dalam kategori kelompok rentan yang memerlukan perlakuan yang khusus dibandingkan dengan narapidana lainnya.

Penggolongan narapidana yang tercantum pada Undang Undang No. 12 tahun 1995 Tentang Pemasyarakatan dirasa sudah cukup baik dalam hal penggolongan Warga Binaan pemasyarakatan khususnya penggolongan berdasarkan usia, sehingga narapidana Lansia bisa mendapatkan pelayanan serta pembinaan yang sesuai berdasarkan undang-undang tersebut. Ditambah dengan adanya PermenKumHAM No.32 tahun 2018 yang dapat menjadi pedoman bagi seluruh Unit Pelaksana Teknis dalam pelaksanaan pemberian pelayanan khusus kepada narapidana lansia.

Penelitian ini dibuat dengan maksud memberikan wawasan terhadap pembaca mengenai pemasyarakatan khususnya mengenai Warga Binaan Pemasyarakatan lansia. Dimana agar masyarakat tahu bahwa meskipun WBP lansia tersebut sedang menjalani hukuman hilang kemerdekaan di dalam Lembaga Pemasyarakatan namun harus tetap diberikan hak haknya sebagaimana lansia mestinya sehingga diharapkan terwujudnya kebijakan yang tepat tentang pelayanan Warga Binaan Lansia di wilayah Pemasyarakatan.

\section{METODOLOGI}

Pada penilitian ini penulis menggunakan metode penelitian pendekan kualittif. Dimana Teknik pengumpulan data dilakukan pada suatu latar alamiah dengan tujuan untuki menafsirkan fenomena yang terdapat di tempat penulis mengambil lokasi penelitian. Pada penelitian ini penulis berusaha menjelaskan dengan cara menggambarkan keadaan yang 
ISSN2621-1351 (online), ISSN 2685-0729 (print

Volume 4 Number 3 (August - October-2021) pp.956-960

ada pada Unit Pelaksana Teknis dalam pemberian pelayanan terhadap narapidana lansia dan membandingkan dengan PermenKUMHAM No.32 Tahun 2018.

\section{HASIL DAN PEMBAHASAN}

Perlakuan khusus terhadap Tahanan dan Narapidana Lanjut Usia yang tercantum pada PermenKumHAM No.32 Tahun 2018 memiliki tujuan agar dapat memenuhi kebutuhan Tahanan atau Narapidana yang telah lanjut usia sehingga diharapkan dapat memelihara kemampuan fisik, mental, dan sosial.

Perlakuan Khusus sebagaimana dimaksud diberikan dalam bentuk:

\section{pemberian bantuan akses keadilan}

Dalam hal ini bantuan yang diberikan berupa pihak Lapas dan Rutan memberikan fasilitas kepada narapidana serta tahanan lansia untuk mendapatkan penasihat hukum. Serta pihak Lapas dan Rutan dapat mencarikan penjamin atau penasihat hukum jika narapidana atau tahanan lansia tersebut tidak memilikinya. Namun tidak semua unit pelaksana teknis di Indonesia dapat optimal dalam melaksanakanan program tersebut. Tetapi terdapat satu unit pelaksana teknis yang dapat menjadi acuan dalam pelaksanaan pelayanan narapidana lansia yaitu Lapas Kelas IIA serang.

\section{pemulihan dan pengembangan fungsi sosial}

narapidana lansia merupakankelompok rentan dimana kondisi mental mereka sangat terdampak dengan situasi Lapas dan Rutan. Tingkat kemungkinan depresi yang tinggi akibat hukuman hilang kemerdekaan juga sangat mungkin terjadi pada narapidana lansia. Oleh karena itu pihak Lapas dan Rutan perlu membuat suatu program pembinaan dimana dapat memulihkan kondisi mental maupun spiritual bagi narapidana lansia tersebut. Seperti halnya yang dilakukan oleh Lapas kelas IIA Serang, dimana Lapas Serang memiliki program inovasi berupa layanan DILAN CARE (layanan peduli disabilitas dan lansia), yang didalamnya terdapat LAKON DILAN (layanan konseling disabilitas dan lanjut usia) yang diperuntukan dalam memberikan bantuan pengembangan pribadi dalam bentuk konseling.

Pada masa pandemi seperti sekarang ini layanan kunjungan bagi narapidana dan tahanan tidak dapat dijalankan, banyak narapidana yang tidak dapat bertemudan bercerita secara langsung dengan keluarga dan saudara mereka. Hal ini dapat menjadi salah satu penyebab terjadinya depresi pada narapidana lansia oleh karena itu dengan adanya layanan Lakon DILAN narapidana dapat mengutarakan keluh kesah mereka kepada petugas yang berada di Lapas atau Rutan.

\section{pemeliharaan dan peningkatan derajat Kesehatan}

pemeliharaan dan peningkatan derajat Kesehatan diberikan kepada narapidana lanisia dalam bentuk penyuluhan informasi tentang Kesehatan bagi lanjut usia, pelaksanaan kegiatan perawatan geriatric/gerontologi, pemberian perawatan paliatif, pemenuhan gizi 


\section{Journal Publicuho}

ISSN2621-1351 (online), ISSN 2685-0729 (print)

Volume 4 Number 3 (August - October), (2021) pp. 956-960

Accredited SINTA SK.NOMOR 28/E/KPT/2019

Open Access at:http://ojs.uho.ac.id/index.php/PUBLICUHO/index DOI: 10.35817/jpu.v4i3.20950

dan nutrisi. Untuk memenuhi pemenuhan Kesehatan tersebut pihak Lapas dan Rutan perlu membentuk sebuah tim medis untuk melakukan kegiatan perawatan Kesehatan sebagaimana yang tercantum diatas.

Seperti yang dilaksanakan Pada Lapas Kelas IIA Serang, dimana Lapas ini memiliki layanan LAPAK DILAN (layanan pemeriksaan Kesehatan disabilitas dan lanjut usia) dimana layanan ini memberikan memberikan penyuluhan dan pemeriksaan Kesehatan kepada narapidana lansia secara aktif. Hal ini juga didukung dengan ketersediaan SDM perawat sebanyak 2 orang dan 1 orang dokter gigi yang dimiliki oleh LAPAS Kelas IIA Serang.

\section{pelindungan keamanan dan keselamatan.}

Setiap narapidana dan tahanan yang terdapat pada lapas dan rutan berhak mendapatkan perlindungan keamanan serta keselamatan selama menjalani masa pidananya. Terlebih pada lansia yang tergolong narapidana kelompok rentan yang perlu perlakuan serta perhatian khusus. Perlindungan keamanan serta keselamatan dapat ditunjang dengan dimulai dari fasilitas penunjang pada blok hunian lansia seperti penggunaan kamar mandi dengan kloset duduk, pengadaan kursi roda, jalan ramp, serta pegangan pada kamar mandi blok hunian WBP lansia.

Namun dalam penerapannya belum semua UPT Pemasyarakatan di Indonesia dapat menerapkan seluruhnya sesuai yang tertera pada Peraturan Menteri Hukum dan HAM No.32 Tahun 2018 tersebut dikrenakan berbagai faktor.

\section{KESIMPULAN}

Penerapan PermenKumHAM No.32 Tahun 2018 pada UPT Pemasyarakatan memang belum semua merata di laksanakan, namun bukan berarti tidak samasekali dilakukan pada unit pelaksana teknis tersebut. Hal tersebut dikarenakan berbagai faktor penghambat dalam pelaksanaan pemenuhan pelayanan kepada WBP lansia berdasarkan Permenkumham No.32 Tahun 2018.

Namun pada Lapas Kelas IIA Serang yang merupakan tolak ukur dalam pemberian pelayanan kepada WBP lansia dapat dikatakan sudah sangat naik dalam hal pemenuhan pelayanan terhadap WBP Lansia. Dengan ditunjang dengan sarana dan prasarana yang tepat dan program inovasi yang sangat tepat maka Lapas Kelas IIA Serang telah memenuhi kriteria dalam pemberian pelayanann terhadap WBP lansia berdasarkan Permenkumham No.32 tahun 2018. 


\section{REFERENSI}

Anggito, A. (2018) Metodologi Penelitian Kualitatif. Sukabumi: CV Jejak

Dilan care, Wujud Inovasi Lapas Serang Dalam Peduli Warga Binaan Lansia. Available from: https://lapasserang.id/dilan-care-wujud-inovasi-lapas-serang-dalam-peduli-wargabinaan-lansia/

Ibnu Masrura, Padmono Wibowo. (2020)." Pelayanan Khusus Warga Binaan Lanjut usia Menurut PERMENKUM HAM RI Nomor 32 tahun 2018 Tentang Perlakuan Bagi Tahanan Dan Narapidana Lanjut Usia." Jurnal Gema Keadilan.

Peraturan Menteri Hukum Dan Hak Asasi Manusia Nomor 32 Tahun 2018 Tentang Perlakuan Bagi Tahanan Dan Narapidana Lanjut Usia. Republik Indonesia, 2018

Undang - Undnag No. 12 Tahun 1995 Tentang Pemasyarakatan. Repbulik Indonesia, 1995 